\title{
The Analysis of Digital Maturity of Schools in Croatia
}

\author{
https://doi.org/10.3991/ijet.v13i06.7844 \\ Igor Balaban $\left.{ }^{\bowtie}\right)$, Nina Begicevic Redjep, Marina Klacmer Calopa \\ University of Zagreb, Varazdin, Croatia \\ igor.balabanefoi.hr
}

\begin{abstract}
This paper presents results of a large pilot project among Croatian primary and secondary schools focused on digital maturity of schools. It explores relationships between indicators that influence the overall digital maturity level of a school with the main aim to identify the main drivers of digital maturity. It also reveals key steps in the development of the Framework for Digitally Mature Schools in Croatia and the instrument for assessing digital maturity of schools. The instrument evaluation involved 151 primary and secondary schools in Croatia that were assessed against maturity levels. Descriptive statistics is used to identify and explain correlations between 38 indicators of digital maturity of schools. Results obtained from the instrument show that 50 percent of schools in Croatia are in the initial phase of maturity and 43 percent of them are e-enabled which in respect to 5 different maturity levels corresponds to levels 2 and 3 respectively. An on-line system developed for this purpose, besides it features the instrument itself and enables schools to benchmark between themselves, identifies critical indicators for each school that require improvement in order for school to make progress against maturity level.
\end{abstract}

Keywords—Digital maturity, maturity framework, instrument, e-Schools

\section{$1 \quad$ Introduction}

The concept of digital maturity of educational institutions is becoming progressively important due to growing importance of Information and Communication Technologies (ICT) in education. Such claims are supported by the European Commission which indicates the significance of digital maturity and offers support throughout its policies and programmes (see the example [6] or [9]). This was also recognized in Croatia and presented a solid ground for starting the e-Schools project, co-financed from the Structural Funds of the European Union which aims to support the development of digitally mature schools in Croatia. This paper defines digitally mature schools as schools with a high level of ICT integration, and with a systematic approach towards using ICT in school management and educational processes. The above mentioned e-Schools project includes the pilot project, started in 2015 and the major project, which will be implemented from 2019 until 2022 based on the results of the pilot project. The pilot project involves participants from 151 primary and secondary schools, which is about $10 \%$ of all schools in Croatia. It is expected that additional 700 schools will be included in the major project. 
This paper reveals several major outcomes of the ongoing pilot project. First, it presents the Framework for Digitally Mature Schools (FDMS) developed within the project. The FDMS describes the concept of digitally mature schools and includes the instrument for assessing digital maturity of schools. Next, the assessment results are presented based on the evaluation conducted in 151 schools involved in the pilot project. In respect with the identified digital maturity levels of the involved schools, a deeper analysis was made and the relationships between 38 indicators that describe the digital maturity concept were analyzed.

\section{Framework for Digitally Mature Schools in Croatia}

In line with the goals of the e-Schools project [4] funded by the European Social Fund and the European Regional Development Fund for the primary and secondary schools in Croatia, we designed the Framework for Digitally Mature Schools (FDMS) as well as the Instrument for self-evaluation and for the external evaluation. Additionally, we developed the software to support the FDMS implementation. The aim of the Framework was to identify the current level of digital maturity of schools in Croatia, to examine possible progress in integration and the efficient use of information and communication technologies (ICT), and to recognize the potential areas for improvement. By our recognition, the FDMS, with the associated instrument and the supporting software, represents a unique and comprehensive tool set created using complex scientific methodology [2].

The development of the FDSM in Croatia underwent several phases with the final goal of developing a framework that contains the evaluation domains and elements of digital maturity which were also recognized in the pre-tertiary education system in Croatia. For the FDMS development we used a complex scientific methodology which includes a set of methods, techniques and instruments such as qualitative analysis and comparability with the 15 internationally recognized digital maturity frameworks that focus on digital technologies or some forms of digital maturity in different sectors; analysis of the existing project documentation, national and international strategies; implementation of semi-structured interviews to gather focused and qualitative data; cards sorting (Q-sorting) method; focus groups analysis and some other methods for defining new framework domains and their elements as well as descriptors related to the maturity levels [2].

Within the analysis of 15 initially recognized digital maturity frameworks, a special attention was paid to the following identified elements: development approach, application area, the existence of accompanying framework, instruments for evaluating the maturity level and for the supporting software and the best practice examples [1]. The analysis revealed DigCompOrg [3] and eLearning Roadmap [8] being two frameworks that best describe the comprehensive field of digital maturity of schools. At later stages, they became the foundation for the construction of a Framework for Digitally Mature Schools in Croatia.

The FDMS is structured into 5 evaluation domains that characterize the pre-tertiary educational institutions in Croatia (1. Planning, Management and Leadership; 2. ICT 
in Learning and Teaching; 3. Development of Digital Competence; 4. ICT Culture; 5. ICT Infrastructure) divided into 38 elements that are described on five maturity levels in the form of a rubric (see Figure 1). Each evaluation domain relates to different aspects of the ICT use and application. The evaluation domain, as well as the elements are complementary and interrelated, and it could be said that they are forming a unified whole [2].

The main instrument used to measure the digital maturity of a school is a rubric (maturity matrix) that initially had 38 rows (digital maturity elements) and five columns (maturity levels). The maturity levels were identified according to [7]. They are: 1 - Basic, 2 - Initial, 3 - e-Enabled, 4 - e-Confident and 5 - e-Mature. For each of the rows (elements), one of the five levels of maturity (columns) were identified according to the existing school digital maturity position. To connect statements and accurately describe the maturity levels, we used mathematical (propositional) logic with logical operations and quantifiers [1].

The Table 1 presents only one out of ten elements in the ICT Infrastructure evaluation domain which is an integral part of the FDMS. Some terms are additionally described in the Glossary which is also a part of the measuring instrument. A similar description was created for each element in all other domains of FDMS.

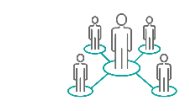

PLANNING, MANAGEMENT AND LEADERSHIP

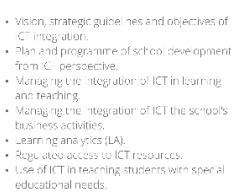

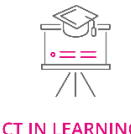

ICT IN LEARNING AND TEACHING

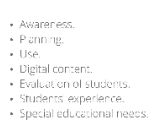

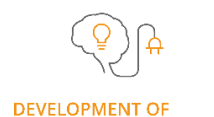

DEVELOPMENT OF

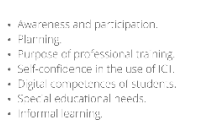

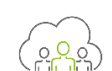

ICT CULTURE

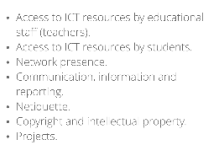

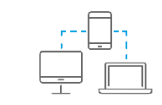

CT INFRASTRUCTURE

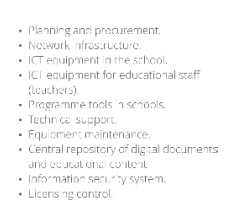

Fig. 1. Overall concept of FDMS

Table 1. Rubric for the element "Software tools in school" in ICT Infrastructure domain

\begin{tabular}{|c|c|c|c|c|c|}
\hline \multirow{2}{*}{ Element } & \multicolumn{5}{|c|}{ Maturity levels } \\
\hline & Basic & Initial & e-Enabled & e-Confident & e-Mature \\
\hline $\begin{array}{l}\text { Software } \\
\text { tools in } \\
\text { school }\end{array}$ & $\begin{array}{l}\text { Only } \\
\text { operating } \\
\text { system } \\
(\mathrm{OS}) \text { is } \\
\text { installed on } \\
\text { all comput- } \\
\text { ers. }\end{array}$ & $\begin{array}{l}\text { Except OS, less than } \\
\text { half of the computer } \\
\text { are equipped with } \\
\text { Office tools*, and } \\
\text { there is no advanced } \\
\text { software** on any } \\
\text { computer. }\end{array}$ & $\begin{array}{l}\text { More than half of } \\
\text { the computers have } \\
\text { Office tools in- } \\
\text { stalled, and less than } \\
\text { half of the comput- } \\
\text { ers have other } \\
\text { specialized soft- } \\
\text { ware** installed. }\end{array}$ & $\begin{array}{l}\text { Almost all comput- } \\
\text { ers have basic } \\
\text { Office tools in- } \\
\text { stalled. More than } \\
\text { half of the comput- } \\
\text { ers have other } \\
\text { specialized software } \\
\text { installed. }\end{array}$ & $\begin{array}{l}\text { Almost all } \\
\text { computers } \\
\text { have Office } \\
\text { tools and } \\
\text { other special- } \\
\text { ized software } \\
\text { installed. }\end{array}$ \\
\hline
\end{tabular}

* Office tools include word processor, spreadsheet editor, presentation tools, etc.

** Specialized software: examples of an application include specialized software packages for teaching and learning (Geogebra, AutoCAD, etc.).

Since the descriptors of all elements are complex, the rubric itself is also complex. This was a reason why we simplified the measuring instrument in a way that we developed the new supporting instrument in a form of questionnaire. The questions or 
answers within the questionnaire are predefined to clearly place the school on a certain level of digital maturity of a particular element in the rubric. So, by combining a few questions and answers, we obtained the maturity level of each element in the rubric.

\section{Results of self-evaluation and external evaluation of school's digital maturity}

The FDMS, along with the instrument and the associated software, has been successfully applied in the process of self-evaluation and external evaluation of 151 primary and secondary schools in Croatia.

The self-evaluation of schools was carried out during June and July 2016, and the role of the evaluators was assigned to principals and teachers from the involved primary and secondary schools, while the external evaluation was conducted by the external evaluators (experts from Faculty of Organization and Informatics, UniZg and The Croatian Academic and Research Network, CARNet) during October 2016. It is important to notice that for the successful self-evaluation, it is always crucial to have a good preparation of the respondents. However, the results of self-evaluation in the schools have shown that the level of implementation awareness and the goals of selfevaluation in Croatia were not satisfactory and that the results were not reflecting the real levels of their digital maturity. Therefore, the external evaluation was the essential post action tool due to the complexity of the instrument itself, but also due to the more objective approach by evaluators based on evidence and established criteria for evaluation as a part of their training. [2].

The evaluation results of 151 schools in Croatia, show that there is a visible difference between the results obtained by self-evaluation and external evaluation (see Figure 2). According to the results of self-evaluation, 1 school was rated as digitally mature (level 5), 6 schools are on the "e-confident" digital maturity level (level 3), 68 schools are estimated to be "e-enabled" (level 3), 76 schools are on the "initial" level (level 2) and there were no schools on the first level ("Basic"). The results of the external evaluation showed that the external evaluators did not evaluate a single school as digitally confident or digitally mature (levels 4 and 5), 27 schools were evaluated as digitally enabled (level 3), 124 schools were estimated to be on the initial level and there were no schools on the first level (basic).

When researching the deviations in the process of self-evaluation and external evaluation of the observed domains, it was noticed that the major deviations occurred in the evaluation domain titled Planning, Management and Leadership because schools were not aware of the comprehensiveness of the strategic documents they were required to have and therefore have faulty reported their current status. Based on current practice, by adapting the strategic documents, and upgrading the existing school documents with ICT strategy, schools could affect their level of maturity. 


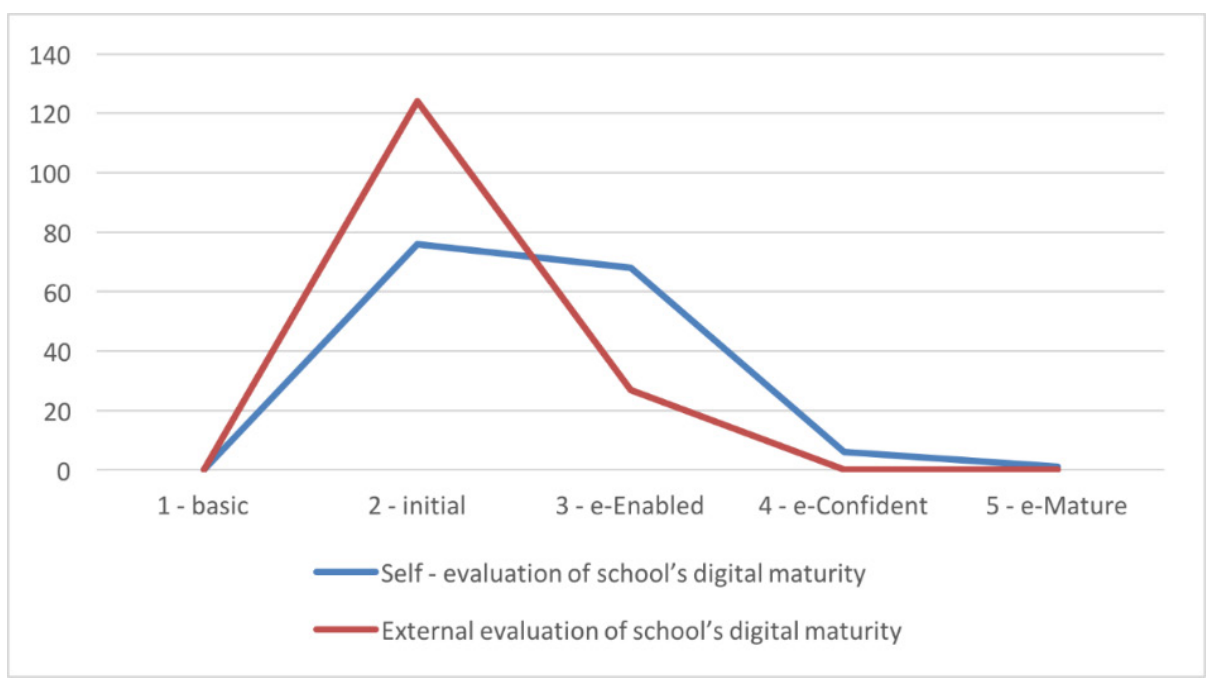

Fig. 2. Summary results of self-evaluation and external evaluation

\section{$4 \quad$ Relationship between digital maturity indicators}

As already mentioned, the performed evaluation involved 151 primary and secondary schools in Croatia, that all underwent two rounds of evaluation that included selfevaluation and external evaluation. In this section, we will focus only on the data gathered by the external evaluation conducted as the second round of the evaluation.

The main aim of the external evaluation was to find: (1) Correlations between indicators within the main domains of the Framework, and (2) Indicators that directly influence the overall digital maturity levels.

\subsection{Relationship within domains}

We started the research by analyzing the correlation matrix for each domain separately where we identified weak and moderate correlations between indicators. The Spearman's correlation coefficient was used to evaluate the relationships? between indicators since all indicators fall into one of the 5 different maturity levels which represents ordinal variables. In this paper, we will focus only on the correlation coefficients around and above 0.3 in respect to [5] who suggest that the correlations sizes below 0.3 indicate negligible connections. However, these are rather arbitrary limits which is the reason why we did not omit the values very near to 0.3 from further interpretation. Therefore, in the following tables (Table 2), the bolded values represent the correlations which are taken into further consideration. Table 2 shows the correlation matrix for the 1st domain - Planning, Management and Leadership.

Within this domain, we found weak correlations between the Vision, strategic guidelines and objectives of ICT integration (PML1) and the Plan and programme of school development from ICT perspective (PML2) $\left(\mathrm{r}_{\mathrm{s}}=.299, \mathrm{p}<0.01\right)$. We can also 
note that the Plan and programme of school development from ICT perspective (PML2) is obviously a very important indicator because it correlates with almost all other indicators within the domain. Consequently, we found that the Plan and programme of school development from ICT perspective (PML2) weakly correlates with the Management of the ICT integration into school's business activities (PML4) $\left(r_{s}=.317, p<0.01\right)$, the Learning analytics (PML5) $\left(r_{s}=.391, p<0.01\right)$, and with the Use of ICT in teaching students with special educational needs (PML7) $\left(\mathrm{r}_{\mathrm{s}}=. .293, \mathrm{p}<\right.$ $0.01)$. Moderate correlation is found with the Management of the ICT integration into learning and teaching (PML3) $\left(\mathrm{r}_{\mathrm{s}}=.485, \mathrm{p}<0.01\right)$.

In the second domain (ICT in Learning and Teaching) we noticed that three indicators are closely interconnected (see Table 3). The Awareness (ICTTL1) weakly correlates with the Planning (ICTTL2) $\left(\mathrm{r}_{\mathrm{s}}=.396, \mathrm{p}<0.01\right)$ and the Use (ICTTL3) $\left(\mathrm{r}_{\mathrm{s}}=.312\right.$, $\mathrm{p}<0.01$ ), while the Planning (ICTTL2) correlates with the Use (ICTTL3) $\left(\mathrm{r}_{\mathrm{s}}=.309\right.$, $\mathrm{p}<0.01)$.

Table 2. Spearman's rho for the Planning, Management and Leadership

\begin{tabular}{|c|c|c|c|c|c|c|c|c|}
\hline \multicolumn{2}{|r|}{ Indicators } & \multirow{2}{*}{$\begin{array}{l}\text { PML1 } \\
1,000\end{array}$} & \multirow[t]{2}{*}{ PML2 } & \multirow[t]{2}{*}{ PML3 } & \multirow[t]{2}{*}{ PML4 } & \multirow[t]{2}{*}{ PML5 } & \multirow[t]{2}{*}{ PML6 } & \multirow[t]{2}{*}{ PML7 } \\
\hline PML1 & $\begin{array}{l}\text { Vision, strategic guidelines and } \\
\text { objectives of ICT integration. }\end{array}$ & & & & & & & \\
\hline PML2 & $\begin{array}{l}\text { Plan and programme of school } \\
\text { development from ICT } \\
\text { perspective. }\end{array}$ & $.299^{* *}$ & 1,000 & & & & & \\
\hline PML3 & $\begin{array}{l}\text { Managing the integration of ICT } \\
\text { in learning and teaching. }\end{array}$ & $.244^{* *}$ & $.485^{* *}$ & 1,000 & & & & \\
\hline PML4 & $\begin{array}{l}\text { Managing the integration of ICT } \\
\text { the school's business activities. }\end{array}$ &, 052 & $.317^{* *}$ & $.210^{* *}$ & 1,000 & & & \\
\hline PML5 & Learning analytics (LA). &, 158 & $.391^{* *}$ & $.214^{* *}$ & $.218^{* *}$ & 1,000 & & \\
\hline PML6 & $\begin{array}{l}\text { Regulated access to ICT re- } \\
\text { sources. }\end{array}$ &,- 018 & $.272^{* *}$ &, 033 &, 114 & $.270^{* *}$ & 1,000 & \\
\hline PML7 & $\begin{array}{l}\text { Use of ICT in teaching students } \\
\text { with special educational needs. }\end{array}$ &, 144 & $.293^{* *}$ & $.207^{*}$ &, 121 &, 120 & $.239^{* *}$ & 1,000 \\
\hline
\end{tabular}

**. Correlation is significant on the 0.01 level (2-tailed).

*. Correlation is significant on the 0.05 level (2-tailed).

Table 3. Spearman's rho for ICT in Learning and Teaching

\begin{tabular}{|c|c|c|c|c|c|c|c|c|}
\hline \multicolumn{2}{|r|}{ Indicators } & \multirow{2}{*}{\begin{tabular}{|c|} 
ICTTL1 \\
1,000
\end{tabular}} & \multirow[t]{2}{*}{ ICTTL2 } & \multirow[t]{2}{*}{ ICTTL3 } & \multirow[t]{2}{*}{ ICTTL4 } & \multirow[t]{2}{*}{ ICTTL5 } & \multirow[t]{2}{*}{ ICTTL6 } & \multirow[t]{2}{*}{ ICTTL7 } \\
\hline ICTTL1 & Awareness. & & & & & & & \\
\hline ICTTL2 & Planning. & $.396^{* *}$ & 1,000 & & & & & \\
\hline ICTTL3 & Use. & $.373^{* *}$ & $.309^{* *}$ & 1,000 & & & & \\
\hline ICTTL4 & Digital content. & $.312^{* *}$ & $.215^{* *}$ & $.353^{* *}$ & 1,000 & & & \\
\hline ICTTL5 & Evaluation of students. &, 109 & $.240^{* *}$ & $.374^{* *}$ & $.164^{*}$ & 1,000 & & \\
\hline ICTTL6 & Students' experience. &, 044 & $.176^{*}$ &, 053 &, 156 & $.225^{* *}$ & 1,000 & \\
\hline ICTTL7 & $\begin{array}{l}\text { Special educational } \\
\text { needs. }\end{array}$ & $.269^{* *}$ & $.311^{* *}$ & $.273^{* *}$ & $.261^{* *}$ &, 116 &, 077 & 1,000 \\
\hline
\end{tabular}

*. Correlation is significant on the 0.05 level (2-tailed).

**. Correlation is significant on the 0.01 level (2-tailed). 
Except between the first three indicators, we also found some other weak correlations. The Awareness (ICTTL1) correlates with the Digital content (ICTTL4) $\left(\mathrm{r}_{\mathrm{s}}=.312, \mathrm{p}<0.01\right)$, the Planning (ICTTL2) with the Special educational needs (ICTTL7) $\left(\mathrm{r}_{\mathrm{s}}=.311, \mathrm{p}<0.01\right)$, and the Use (ICTTL3) with the Digital content (ICTTL4) and the Evaluation of students (ICTTL5) $\left(\mathrm{r}_{\mathrm{s}}=.374, \mathrm{p}<0.01\right)$.

The largest number of correlations between indicators is found within domain the Development of Digital Competence (see Table 4). The Awareness and participation (DDC1) was identified as the most important indicator in the domain due to its moderate correlation with the Purpose of professional training (DDC3) $\left(r_{s}=.502, p<0.01\right)$ and its weak correlations with the Self-confidence in the use of ICT $\left(r_{s}=.408, p<0.01\right)$, the Digital competences of students (DDC5) $\left(r_{s}=.300, p<0.01\right)$ and the Informal learning $(\mathrm{DDC} 7)\left(\mathrm{r}_{\mathrm{s}}=.315, \mathrm{p}<0.01\right)$.

Table 4. Spearman's rho for Development of Digital Competence

\begin{tabular}{|c|c|c|c|c|c|c|c|c|}
\hline \multicolumn{2}{|r|}{ Indicators } & DDC1 & DDC2 & DDC3 & DDC4 & DDC5 & DDC6 & DDC7 \\
\hline DDC1 & Awareness and participation. & 1,000 & & & & & & \\
\hline DDC2 & Planning. & $.267^{* *}$ & 1,000 & & & & & \\
\hline DDC3 & Purpose of professional training. & $.502^{* *}$ & $.395^{* *}$ & 1,000 & & & & \\
\hline DDC4 & Self-confidence in the use of ICT. & $.408^{* *}$ & $.174^{*}$ & $.304^{* *}$ & 1,000 & & & \\
\hline DDC5 & Digital competences of students. & $.300^{* *}$ & $.291^{* *}$ & $.389^{* * *}$ & $.314^{* *}$ & 1,000 & & \\
\hline DDC6 & Special educational needs. &, 128 & $.274^{* *}$ & $.219^{* *}$ & $.227^{* *}$ & $.162^{*}$ & 1,000 & \\
\hline DDC7 & Informal learning. & $.315^{* *}$ & $.301^{* *}$ & $.465^{* *}$ & $.309^{* *}$ & $.307^{* *}$ &, 089 & 1,000 \\
\hline
\end{tabular}

**. Correlation is significant on the 0.01 level (2-tailed).

*. Correlation is significant on the 0.05 level (2-tailed).

The Planning (DDC2) is weakly connected with the Purpose of professional training (DDC3) $\left(\mathrm{r}_{\mathrm{s}}=.395, \mathrm{p}<0.01\right)$, the Digital competences of students (DDC5) $\left(\mathrm{r}_{\mathrm{s}}=.291\right.$, $\mathrm{p}<0.01)$ and the Informal learning (DDC7) $\left(\mathrm{r}_{\mathrm{s}}=.301, \mathrm{p}<0.01\right)$. The Purpose of professional training (DDC3) weakly correlates with the Digital competences of students (DDC5) $\left(\mathrm{r}_{\mathrm{s}}=.389, \mathrm{p}<0.01\right)$, but shows tendency towards moderate relationship with the Informal learning (DDC7). Finally, the Digital competences of students (DDC5) weakly correlates with the Informal learning (DDC7) $\left(r_{s}=.307, p<0.01\right)$.

Table 5 presents correlation coefficients for the domain the ICT culture. Here we found one moderate correlation between the Access to ICT resources by educational staff (teachers) (ICTC1) and the Access to ICT resources by students (ICTC2) $(\mathrm{rs}=.522, \mathrm{p}<0.01)$. Next, we found that the Communication, information and reporting (ICTC4) is a central indicator of this domain because it has the largest number of correlations with other indicators. In this respect, it correlates with the Access to ICT resources by educational staff (teachers) (ICTC1) $\left(\mathrm{r}_{\mathrm{s}}=.414, \mathrm{p}<0.01\right)$, the Access to ICT resources by students $\left(\right.$ ICTC2) $\left(\mathrm{r}_{\mathrm{s}}=.326, \mathrm{p}<0.01\right)$ and with the Netiquette (ICTC5) $\left(\mathrm{r}_{\mathrm{s}}=.406, \mathrm{p}<0.01\right)$. Within this domain we also found weak correlation between the Netiquette (ICTC5) and the Projects (ICTC7) $\left(\mathrm{r}_{\mathrm{s}}=.336, \mathrm{p}<0.01\right)$.

Within the last domain we found several weak correlations presented in Table 6. The Network infrastructure (ICTI2) correlates with the Planning and procurement (ICTC1) $\left(\mathrm{r}_{\mathrm{s}}=.358, \mathrm{p}<0.01\right)$ and with the ICT equipment for educational staff (teach- 
ers) (ICTI4) $\left(\mathrm{r}_{\mathrm{s}}=.291, \mathrm{p}<0.01\right)$. The ICT equipment in the school (ICTI3) correlates with the ICT equipment for educational staff (teachers) (ICTI4) $\left(\mathrm{r}_{\mathrm{s}}=.309, \mathrm{p}<0.01\right)$ and with the Software tools in schools (ICTI5) $\left(r_{s}=.347, p<0.01\right)$. The last correlation is found between the Information security system (ICTI9) and the Licensing control (ICTI19) $\left(\mathrm{r}_{\mathrm{s}}=.423, \mathrm{p}<0.01\right)$.

Table 5. Spearman's rho for ICT Culture

\begin{tabular}{|c|c|c|c|c|c|c|c|c|}
\hline \multicolumn{2}{|r|}{ Indicators } & \multirow{2}{*}{\begin{tabular}{|c|} 
ICTC1 \\
1,000
\end{tabular}} & \multirow[t]{2}{*}{ ICTC2 } & \multirow[t]{2}{*}{ ICTC3 } & \multirow[t]{2}{*}{ ICTC4 } & \multirow[t]{2}{*}{ ICTC5 } & \multirow[t]{2}{*}{ ICTC6 } & \multirow[t]{2}{*}{ ICTC7 } \\
\hline ICTC1 & $\begin{array}{l}\text { Access to ICT resources by educa- } \\
\text { tional staff (teachers). }\end{array}$ & & & & & & & \\
\hline ICTC2 & Access to ICT resources by students. & $.522^{* *}$ & 1,000 & & & & & \\
\hline ICTC3 & Internet presence. & $.263^{* *}$ & $.164^{*}$ & 1,000 & & & & \\
\hline ICTC4 & $\begin{array}{l}\text { Communication, information and } \\
\text { reporting. }\end{array}$ & $.414^{* *}$ & $.326^{* *}$ &, 145 & 1,000 & & & \\
\hline ICTC5 & Netiquette. & $.162^{*}$ & 138 & 089 & $.406^{* *}$ & 1,000 & & \\
\hline ICTC6 & Copyright and intellectual property. &,- 100 &,- 016 &, 012 &, 052 & , 106 & 1,000 & \\
\hline ICTC7 & Projects. & $.219^{* *}$ & $.282^{* *}$ & $259^{* *}$ & $.183^{*}$ & $.336^{* *}$ & 147 & 1,000 \\
\hline
\end{tabular}

**. Correlation is significant on the 0.01 level (2-tailed).

*. Correlation is significant on the 0.05 level (2-tailed).

Table 6. Spearman's rho for ICT Infrastructure

\begin{tabular}{|c|c|c|c|c|c|c|c|c|c|c|c|}
\hline & Indicators & $\begin{array}{c}\text { ICTI } \\
1\end{array}$ & ICTI2 & ICTI3 & ICTI4 & ICTI5 & ICTI6 & ICTI7 & ICTI8 & ICTI9 & ICTI10 \\
\hline ICTI1 & $\begin{array}{l}\text { Planning and } \\
\text { procurement. }\end{array}$ & 1,000 & & & & & & & & & \\
\hline ICTI2 & $\begin{array}{l}\text { Network infrastruc- } \\
\text { ture. }\end{array}$ & $.358^{* *}$ & 1,000 & & & & & & & & \\
\hline ICTI3 & $\begin{array}{l}\text { ICT equipment in } \\
\text { the school. }\end{array}$ &, 133 & $.203^{*}$ & 1,000 & & & & & & & \\
\hline ICTI4 & $\begin{array}{l}\text { ICT equipment for } \\
\text { educational staff } \\
\text { (teachers). }\end{array}$ & $.210^{* *}$ & $.291^{* *}$ & $.309^{* *}$ & 1,000 & & & & & & \\
\hline ICTI5 & $\begin{array}{l}\text { Software tools in } \\
\text { schools. }\end{array}$ &, 145 & $.245^{* *}$ & $.347^{* *}$ &, 145 & 1,000 & & & & & \\
\hline ICTI6 & Technical support. &, 095 &, 123 & $.203^{*}$ & $.201^{*}$ &, 119 & 1,000 & & & & \\
\hline ICTI7 & $\begin{array}{l}\text { Equipment mainte- } \\
\text { nance. }\end{array}$ &,- 052 &, 019 &, 142 & $.172^{*}$ &, 053 & $.243^{* *}$ & 1,000 & & & \\
\hline ICTI8 & $\begin{array}{l}\text { Central repository } \\
\text { of digital docu- } \\
\text { ments and educa- } \\
\text { tional content. }\end{array}$ & $.195^{*}$ &, 153 & $.183^{*}$ & $.182^{*}$ &, 123 &, 120 &,- 088 & 1,000 & & \\
\hline ICTI9 & $\begin{array}{l}\text { Information securi- } \\
\text { ty system. }\end{array}$ &, 019 &, 087 & $.220^{* *}$ & $.208^{*}$ & $.273^{* *}$ & $.236^{* *}$ &, 139 & $.212^{* *}$ & 1,000 & \\
\hline ICTI10 & Licensing control. &, 040 &,- 069 &, 134 &, 127 & $.174^{*}$ &, 120 &,- 045 &, 157 & $.423^{* *}$ & 1,000 \\
\hline
\end{tabular}

**. Correlation is significant at the 0.01 level (2-tailed).

*. Correlation is significant at the 0.05 level (2-tailed). 


\subsection{Relationship between indicators and maturity levels}

The next step in our analysis was to research the correlations between maturity indicators and maturity levels in order to identify possible dependencies and maturity indicators that directly influence the final maturity level of a school.

We analyzed the correlation matrix with all indicators and calculated the maturity levels for 151 schools. The total of 21 indicators were found to influence the maturity level of a school with significance level of $\mathrm{p}<0.01$ and are listed below by domains:

1. Planning, Management and Leadership: Plan and programme of school development from ICT perspective (PML2) $\left(\mathrm{r}_{\mathrm{s}}=.407\right)$; Managing the integration of ICT in learning and teaching (PML3) $\left(\mathrm{r}_{\mathrm{s}}=.441\right)$; Learning analytics (LA) (PML5) $\left(\mathrm{r}_{\mathrm{s}}=.383\right)$; Regulated access to ICT resources (PML6) $\left(\mathrm{r}_{\mathrm{s}}=.298\right)$; Use of ICT in teaching students with special educational needs (PML7) $\left(\mathrm{r}_{\mathrm{s}}=.388\right)$.

2. ICT in Learning and Teaching: Awareness (ICTTL1) $\left(\mathrm{r}_{\mathrm{s}}=.372\right)$, Use (ICTTL3) $\left(\mathrm{r}_{\mathrm{s}}=.432\right)$; Digital content (ICTTL4) $\left(\mathrm{r}_{\mathrm{s}}=.390\right)$.

3. Development of Digital Competence: Awareness and participation (DDC1) $\left(\mathrm{r}_{\mathrm{s}}=.389\right)$; Planning (DDC2) $\left(\mathrm{r}_{\mathrm{s}}=.342\right)$; Purpose of professional training (DDC3) $\left(r_{s}=.381\right)$; Self-confidence in the use of ICT (DDC4) $\left(r_{s}=.350\right)$; Informal Learning (DDC7) $\left(r_{\mathrm{s}}=.453\right)$.

4. ICT Culture: Access to ICT resources by educational staff (teachers) (ICTC1) $\left(r_{\mathrm{s}}=.364\right)$; Access to ICT resources by students (ICTC2) $\left(\mathrm{r}_{\mathrm{s}}=.468\right)$; Communication, information and reporting (ICTC4) $\left(\mathrm{r}_{\mathrm{s}}=.331\right)$; Projects (ICTC7) $\left(\mathrm{r}_{\mathrm{s}}=.463\right)$.

5. ICT Infrastructure: Planning and procurement (ICTI1) $\left(\mathrm{r}_{\mathrm{s}}=.330\right)$; Network infrastructure (ICTI2) $\left(\mathrm{r}_{\mathrm{s}}=.311\right)$; ICT equipment in the school (ICTI3) $\left(\mathrm{r}_{\mathrm{s}}=.431\right)$; ICT equipment for educational staff (teachers) (ICTI4) $\left(\mathrm{r}_{\mathrm{s}}=.334\right)$.

\section{Discussion}

According to the above presented correlation analysis, it is evident that some indicators play an important role within their domains. We showed that the Plan and programme of school development from ICT perspective plays very important role in the first domain because it positively affects many other indicators and that it also affects the overall maturity level of a school. This, somehow, justifies the purpose of such document which is to set a solid ground for all activities that involve ICT. Without a proper plan, it would not be possible to implement and utilize the ICT in teaching and learning. Furthermore, it needs to be noted that this indicator is also connected with the Management of ICT integration into teaching and learning indicating once again that the Plan is indeed a backbone of the ICT implementation and usage primarily in teaching and learning.

In the second domain, we identified the Awareness indicator being the trigger for others. This can be justified by the meaning of the indicator itself. Namely, if there is no awareness of the potentials of the ICT in teaching and learning, all other activities such as planning, usage of the ICT, etc. would probably be very restricted or would not occur at all. 
The third domain elicits once again the Awareness and participation as the prerequisites for the development of digital competences. It was shown that, in a broad sense, the mentioned indicator helps to recognize the purpose of the professional training, as well to become more self-confident user of the ICT. Next, the same indicator, if present, will enhance and support the development of digital competences of students, as well as the informal learning, which needs to be encouraged and recognized in a formal schooling system.

The fourth domain did not reveal any key indicator. However, it showed that the Access to the ICT resources for students and for teachers are very related, meaning that if a school sets up the ICT resources, most of them will be available to both, students and teachers, or that at least, if a new equipment is installed for students, a part of that equipment will be available to teachers as well.

The last domain also did not reveal any key indicators, but showed that the network infrastructure greatly depends on the planning procedures, and that the equipment for teachers is purchased taking into account the network infrastructure specifications. This could mean that if a wireless network is present, there is a high probability that teachers will be equipped with laptops and tablets, while it is rarely the case where the wireless network is not present throughout the school. One interesting finding is that a school will pay more attention to licensing control if some kind of information security procedures are developed.

Finally, it needs to be noted that the school management plays very important role in the digital maturity of a school. It was shown that a well written and balanced plan for school development from the ICT perspective, along with the good management of ICT integration in teaching and learning, present a solid ground for digitally mature schools. Most of the "Awareness" indicators are based on a good planning being the triggers for other activities in their domains. Also, the planning within other domains refers to a general plan established in the first domain.

\section{Conclusion}

This paper presented the Framework for Digitally Mature Schools which serves to identify the domains and elements that contribute to the digital maturity of schools, and the supporting instrument designed to assess the level of digital maturity of schools and to identify the areas of possible improvements in the context of the school's digital maturity. Because of the generic characteristics, the developed Framework, together with the instrument and the software, can be adapted to similar systems in other countries in order to determine the digital maturity of schools.

The results of the external evaluation revealed the fact that the majority of the evaluated schools in Croatia are on levels 2 or 3 which means that there is a room from their progress. A dozens of indicators were revealed that are more or less interconnected and dependent and that influence the overall digital maturity level of a school. Based on the results, it is evident that some indicators play an important role within their domains so the schools should aim to raise the maturity of these indica- 
tors first which will reflect in raising the maturity of the domain and in the end, in the general maturity level of a school.

In the next period, all involved schools will receive support in terms of equipment and will be involved in the workshops on how to write strategic documents, i.e. Plan and programme of school development from ICT perspective, and a dozen of education programmes developed with the aim to raise the awareness of school management and teachers about possible implications of ICT in teaching and learning. At the end of the project, the additional round of evaluation will be performed in order to find out if the planned activities were implemented and if they resulted in overall improvement of the digital maturity level of the involved schools.

\section{$7 \quad$ References}

[1] Begičević Ređep, N. et al. (2017a). Framework for Digitally Mature Primary and Secondary Schools in Croatia with the relevant instrument. e-Schools: Establishing a System for Developing Digitally Mature Schools (pilot project).

[2] Begičević Ređep, N. at al. (2017b). Framework for Digitally Mature Schools. Conference Proceedings. Edited by Airina Volungeviciene, András Szücs on behalf of the European Distance and E-Learning Network European Distance and E-Learning Network, EDEN 2017. Annual Conference. Sweden. 13-16 June. pp 360-371

[3] DigCompOrg. (2015). Digitally Competent Educational Organizations. Retrieved from https://ec.europa.eu/jrc/en/digcomporg/framework

[4] e-Schools: Establishing a System for the Development of Digitally Mature Schools (pilot project). Retrieved from http://www.carnet.hr/e-skole

[5] Hinkle DE, Wiersma W, Jurs SG. Applied Statistics for the Behavioral Sciences. 5th ed. Boston: Houghton Mifflin; 2003.

[6] Kampylis, P., Punie, Y. \& Devine, J., Promoting Effective Digital-Age Learning - A European Framework for Digitally-Competent Educational Organisations, 2015.

[7] Love, D., Mckean, G. \& Gathercoal, P. (2004). Portfolios to webfolios and beyond: levels of maturation. Educause quarterly, no.2, pp. 24-37

[8] National Centre for Technology in Education. E-learning Roadmap. Ireland. Retrieved from http://www.ncte.ie/elearningplan/roadmap/

[9] SCALE CCR, Up-scaling Creative Classrooms in Europe. Retrieved January 16, 2017 from http://is.jrc.ec.europa.eu/pages/EAP/SCALECCR.html.

\section{Authors}

Igor Balaban is assistant professor at FOI. Igor obtained Master's Degree in information systems from University of Zagreb, FOI and $\mathrm{PhD}$ in information science also at University of Zagreb, FOI. He joined FOI in September 2004. He was engaged in several European and national research and professional projects. He was also a coordinator of LLP KA3 ICT EPNET project (europortfolio.org) and is currently a local coordinator of $\mathrm{H} 2020$ project where FOI is a partner. He authored and coauthored 30+ scientific and professional papers and is involved with European Commissions' Joint Research Centre work on European Framework for Digitally- 
Competent Educational Organizations' and on Development of the System of Digital Maturity of Schools. He organized and conducted dozens of workshops and talked at more than 20 conferences. He is also a reviewer for several highly respected journals such as Computers \& Education, International Journal of ePortfolio and International Journal of Information Systems. His main field of interest is technology supported learning with special focus on adaptivity and personalization in learning environments (ePortfolios, Open badges, adaptive knowledge assessment).

Nina Begičević Ređep is associate professor of business decision making and decision theory, Vice-dean for research and international relations (2015-today), former Vicedean for business affairs (2011-2015) at the Faculty of Organization and Informatics. She is an expert in strategic planning and decision making, especially for multi-criteria decision making method called the AHP with focus on e-learning and educational technologies. She spent one semester at Katz Graduate School of Business, University of Pittsburgh (USA) in the framework of the JFDP program of the U.S. Department of State. She was a researcher and senior expert within 17 international and national projects ( 5 scientific projects, 3 ESF projects, 4 IPA projects, 2 TEMPUS projects, 3 EUREKA projects, etc.) in the field of education, e-learning and decision making. She is an author and co-author of 40 research articles. She is also a reviewer for several highly respected journals and a member of the editorial board of International Journal of the Analytic Hierarchy Process.

Marina Klačmer Čalopa is associate professor of several organizational and economics university subjects at FOI which focus on the business plan, strategic management, competitive intelligence, lean methodology, capital markets and finance, institutional investors and human resource management. She is the Head of graduate study programme at FOI, Economics of Entrepreneurship and an operative assistant of postgraduate specialist study Business Systems Management. She coordinated two international (IPA, IP) and one national project (ESF) related to entrepreneurship, education and business skills and has participated on several national and international projects. Also, she published several papers in these fields. She is also a reviewer for several highly respected journals.

Article submitted 16 October 2017. Final acceptance 23 April 2018. Final version published as submitted by the authors. 